\title{
Fluorene-Based Oligomers for Highly Efficient and Stable Organic Blue-Light-Emitting Diodes
}

\author{
By Chang-Gua Zhen, Zhi-Kuan Chen, * Qin-De Liu, Yan-Feng Dai, \\ Richard Yee Cheong Shin, Soon-Yee Chang, and John Kieffer*:
}

Organic light-emitting diodes (OLEDs) have great potential for applications such as flat panel displays and solid-state lighting. ${ }^{[1-6]}$ Many green- and red-light-emitting organic materials have been developed for full-color displays but highly efficient and stable blue-light-emitting organic materials are still rare. ${ }^{[7-10]}$ Due to the large band-gap of blue-light emitters, it is difficult to inject holes from the anode as well as electrons from the cathode in blue-light OLEDs. Promising candidates for blue-light-emitting materials include fluorene-based polymers and oligomers, due to their high photoluminescent quantum yield (PLQY), good thermal stability, and excellent solubility. ${ }^{[11-13]}$ In this communication, we report a series of new blue-light-emitting materials consisting of oligofluorenyl blocks and electron-donating/electron-withdrawing groups, which facilitate the injection and transport of both holes and electrons. The device performance of undoped and doped devices indicates that they are very promising for OLEDs, with essential elements of high efficiency, good stability, and color purity for pure-blue emission.

The target blue-light-emitting compounds were synthesized through three key steps (Scheme 1). First, 4-iodoaniline was coupled with carbazole through an Ullmann coupling reaction. In our first attempt, where $N, N$-dimethylacetamide (DMAc) was used as solvent, the reaction solution was heated at $160^{\circ} \mathrm{C}$ for $24 \mathrm{~h}$, and $76 \%$ yield of compound A was achieved. In our second attempt with diphenyl ether as solvent, the temperature was raised to $190{ }^{\circ} \mathrm{C}$ and the reaction yielded $92 \%$ of desired product. Compound A was then coupled with dibromo-oligofluorene (B1-B3), catalyzed by $\mathrm{Pd}(\mathrm{OAc})_{2}$, to afford compounds C1 to C3, which were eventually end-capped with cyanophenyl groups through a Suzuki coupling reaction. The three coupling reactions produced an overall yield of 55\%, 37\%, and 33\% for D1, D2, and D3, respectively.

The physical properties of the compounds are summarized in Table 1. All three compounds show high photoluminescent quantum yields, ranging from $59 \%$ to $64 \%$ in chloroform solution. With the number of fluorene units increasing from 1 to

[*] Dr. Z.-K. Chen, C.-G. Zhen, Dr. Q.-D. Liu, Y.-F. Dai, Dr. R. Y. C. Shin, S.-Y. Chang

Institute of Materials Research and Engineering

3 Research Link, Singapore 117602 (Singapore)

E-mail: zk-chen@imre.a-star.edu.sg

Prof. J. Kieffer, C.-G. Zhen

Department of Materials Science and Engineering

University of Michigan

Ann Arbor, MI $48109-2136$ (USA)

E-mail: kieffer@umich.edu

DOI: 10.1002/adma.200900095
3 , the optical properties change remarkably. The optical bandgaps determined from the $\lambda_{0-0}$ absorption-band edge are 2.78 , 2.81, and 2.89 eV for D1, D2 and D3, respectively. The absorption maximum in the UV-vis spectrum of D3 in chloroform solution is blue-shifted by $9 \mathrm{~nm}$, and the peak of photoluminescence (PL) spectrum of the thin film is largely blue-shifted by $33 \mathrm{~nm}$ compared with D1, as shown in Figure 1a. The OLED device performances also depend on the number of fluorene units, which will be described below.

The preparation of the electroluminescent devices is briefly described as follows (see Experimental section): poly(3,4-ethylenedioxythiophene):poly(styrenesulfonate) (PEDOT:PSS) and the light-emitting layer were spin-coated from solutions onto indium tin oxide (ITO) surfaces sequentially. 1,3,5-tris(phenyl-2-benzimidazolyl)benzene (TPBI) and the cathode were thermally deposited in vacuum of $1 \times 10^{-5} \mathrm{~Pa}$. The device performances are summarized in Table 2. For the undoped devices (Fig. 2), the emissions from D1, D2, and D3 are peaked at $493 \mathrm{~nm}, 493 \mathrm{~nm}$, and $446 \mathrm{~nm}$, with Commission Internationale de L'eclairage (CIE) color coordinates of $(0.176,0.397),(0.148,0.280)$, and $(0.150,0.148)$, respectively. The emission from D3 is in the limit of pure-blue emission, with CIE $x+y<0.30$. The turn-on voltage $\left(\right.$ at $\left.1 \mathrm{~cd} \mathrm{~m}^{-2}\right)$ for all these devices is $\approx 3.0 \mathrm{~V}$, almost as low as the optical band-gaps of the blue emitters. The highest brightness is $23965 \mathrm{~cd} \mathrm{~m}^{-2}$ for $\mathrm{D} 1,38327 \mathrm{~cd} \mathrm{~m}^{-2}$ for
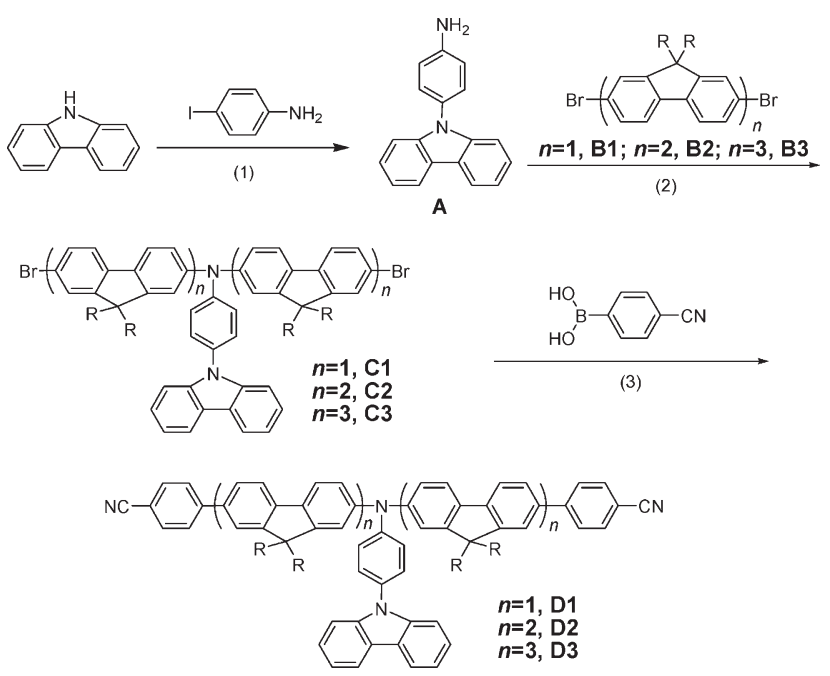

Scheme 1. Synthesis of blue-light emitters D1, D2, and D3. Reagents and conditions: 1) $\mathrm{Cu}_{2} \mathrm{O}$, diphenyl ether, $190^{\circ} \mathrm{C}, 24 \mathrm{~h}, 92 \%$; 2$) \mathrm{Pd}(\mathrm{OAc})_{2}$, DPPF, $\mathrm{NaOtBu}$, toluene, $110^{\circ} \mathrm{C}, 18 \mathrm{~h}, 53-68 \%$; and 3) $\mathrm{Pd}\left(\mathrm{PPh}_{3}\right)_{4}$, toluene, $2 \mathrm{M}$ $\mathrm{Na}_{2} \mathrm{CO}_{3}, 110^{\circ} \mathrm{C}, 24 \mathrm{~h}, 60-87 \%$. 
Table 1. Physical properties of D1, D2, and D3.

\begin{tabular}{|c|c|c|c|c|c|c|c|}
\hline Compound & UV-Vis $\lambda_{\max }[\mathrm{nm}][\mathrm{a}]$ & Bandgap $[\mathrm{eV}][\mathrm{c}]$ & HOMO/LUMO [eV] [d] & $\mathrm{PL} \lambda_{\max }[\mathrm{nm}][\mathrm{b}]$ & PLQY [\%] & $T_{g}\left[{ }^{\circ} \mathrm{C}\right]$ & $T_{\mathrm{d}}\left[{ }^{\circ} \mathrm{C}\right]$ \\
\hline D1 & 389 & 2.78 & $-5.17 /-2.39$ & 489 & 59 & 96 & 421 \\
\hline D2 & 389 & 2.81 & $-5.12 /-2.31$ & 472 & 59 & 102 & 424 \\
\hline D3 & 380 & 2.89 & $-5.05 /-2.16$ & 456 & 64 & 101 & 424 \\
\hline
\end{tabular}

[a] The UV-vis spectra and PLQY were obtained from chloroform solution; [b] PL spectra were obtained from solid-state thin films; [c] The band-gaps were calculated from the onset of UV-vis spectra. [d] HOMO values were determined by the onset of CV measurements, and LUMO values were calculated from HOMO values and band-gaps.
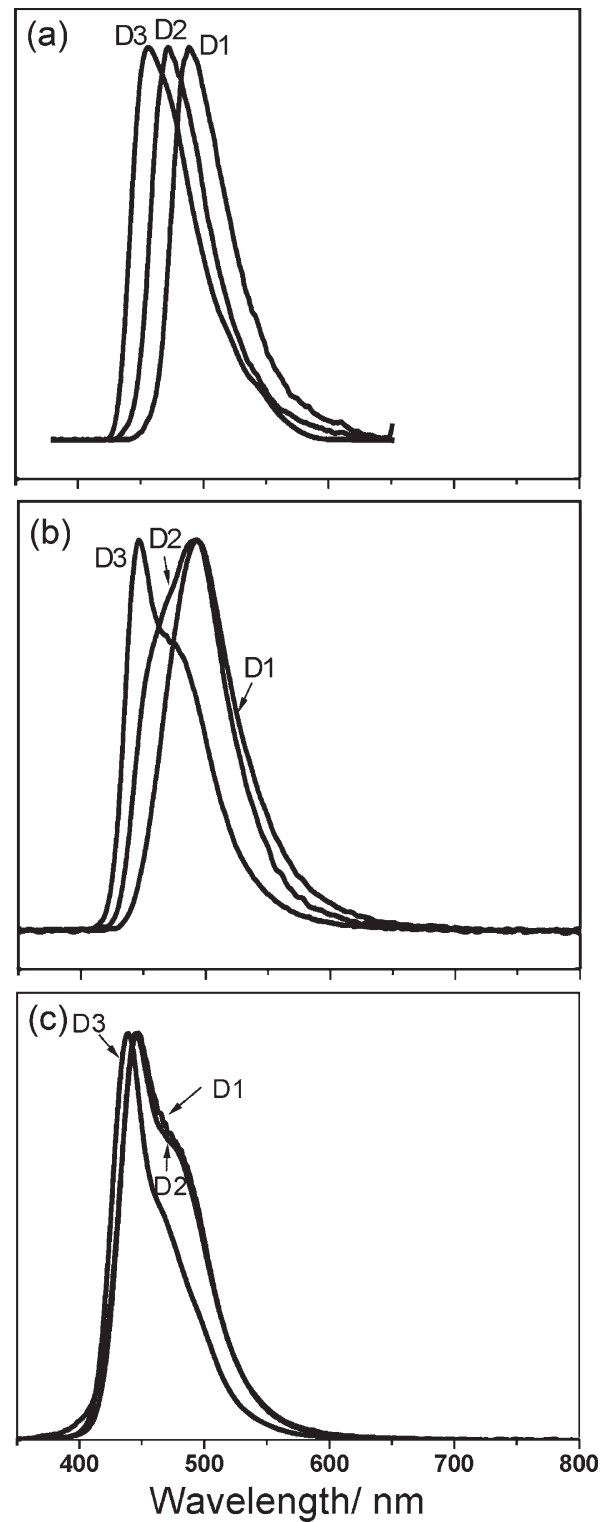

Figure 1. Normalized PL and EL spectra of D1, D2, and D3. a) PL of solid thin films. b) EL of undoped devices. c) EL of doped devices (4\% in CBP).

D2, and $19416 \mathrm{~cd} \mathrm{~m}^{-2}$ for D3. The maximum external quantum efficiencies (EQE) for D1, D2, and D3, are $2.6 \%$ at $2175 \mathrm{~cd} \mathrm{~m}^{-2}$, $6.1 \%$ at $496 \mathrm{~cd} \mathrm{~m}^{-2}$ and $4.5 \%$ at $408 \mathrm{~cd} \mathrm{~m}^{-2}$, respectively.

The EQE of these blue-light OLEDs are quite high using these oligomers as emitters. One possible reason for the high EQE may be the bipolar structure of the molecules, which enable both hole and electron injection and transportation efficiently. ${ }^{[14-16]}$ To investigate the effect of electron-withdrawing cyanophenyl groups of the oligomers on the device performance, a reference compound D2' was synthesized. D2' has the same backbone as that of D2, but without the cyanophenyl groups. In a same device configuration, a maximum external quantum efficiency of $2.0 \%$ for $\mathbf{D} 2{ }^{\prime}$ was obtained at $84 \mathrm{~cd} \mathrm{~m}^{-2}$, and the efficiency dropped to $0.62 \%$ at $552 \mathrm{~cd} \mathrm{~m}^{-2}$. These efficiencies are much lower than those of D2. This result indicates that the cyanophenyl group plays a critical role for the device performance. The superiority in quantum efficiencies of Dn over D2' should be ascribed to the enhanced electron injection and transportation in the oligomers due to cyanophenyl groups.

Not only are the EQE of the devices attractive, but their stability is also promising. For device D3, the pure-blue emission was independent of operating current density in a wide range, that is, from 0.5 to $170 \mathrm{mAcm}^{-2}$. The device D3 was stable even under continuous operation at intense brightness. After operating in nitrogen atmosphere for $10 \mathrm{~h}$ at $1000 \mathrm{~cd} \mathrm{~m}^{-2}$, the CIE color coordinates of the device were $(0.148,0.162)$, showing a very slight shift from $(0.150,0.148)$ of the fresh device. Furthermore, the pure-blue emission was also thermally stable. For comparison, a spin-coated D3 layer was annealed at $150{ }^{\circ} \mathrm{C}$ in air for $2 \mathrm{~h}\left(T_{\mathrm{g}}=101^{\circ} \mathrm{C}\right)$ before the deposition of TPBI. The EL spectrum of the annealed device is almost the same as that of the unannealed one. The device efficiency is also independent on thermal aging treatment. The maximum EQE from the annealed device is $4.5 \%$ at $303 \mathrm{~cd} \mathrm{~m}^{-2}$, equal to the unannealed one.

The optical and electrical properties (solid-state PL, EL, optical band-gap, and EQE of the devices) depend on the number of fluorene units in the molecules. With increasing fluorene units, the optical band-gap, which is determined from the absorption edge of UV-vis spectrum, increases. The peaks of PL spectra of solid-state thin films and EL spectra shift to shorter wavelengths, as shown in Figure $1 \mathrm{a}$ and $\mathrm{b}$. These are contrary to the common fact that with increasing conjugation length of the organic molecules the band-gap should be smaller so that the PL and EL should be peaking in the longer-wavelength range. To investigate the reasons for these anomalies, we carried out quantum chemistry calculations (see Experimental section). The calculated highest occupied molecular orbital-lowest unoccupied molecular orbital (HOMO-LUMO) gap for single molecules of D1, D2, and D3 are 3.197, 3.065, and 3.007 eV, respectively, which is consistent with the expectation that the band-gap will decrease from D1 to D3. The blue shift of PL and EL with increasing fluorene units is most likely due to intermolecular effects. Indeed, the dipole moments obtained from calculation are 4.564, 2.822, and 
Table 2. Device performance of undoped and doped devices (4\% in CBP).

\begin{tabular}{|c|c|c|c|c|c|c|}
\hline & \multicolumn{2}{|c|}{ D1 } & \multicolumn{2}{|c|}{ D2 } & \multicolumn{2}{|c|}{ D3 } \\
\hline & undoped & doped & undoped & doped & undoped & doped \\
\hline $\mathrm{EL} \lambda_{\max }[\mathrm{nm}]$ & 493 & 446 & 493 & 445 & 446 & 439 \\
\hline $\mathrm{CIE}[x, \gamma]$ & $0.176,0.397$ & $0.147,0.130$ & $0.148,0.280$ & $0.149,0.132$ & $0.150,0.148$ & $0.151,0.088$ \\
\hline$V_{\text {turn-on }}[\mathrm{V}]$ & 3.0 & 3.4 & 3.0 & 4.0 & 2.9 & 4.0 \\
\hline$L_{\max }\left[\mathrm{cd} \mathrm{m}^{-2}\right]$ & 23965 & 19225 & 38327 & 28008 & 19416 & 20924 \\
\hline $\mathrm{EQE}_{\max }[\%]$ & 2.6 & 8.1 & 6.1 & 8.6 & 4.5 & 8.2 \\
\hline
\end{tabular}

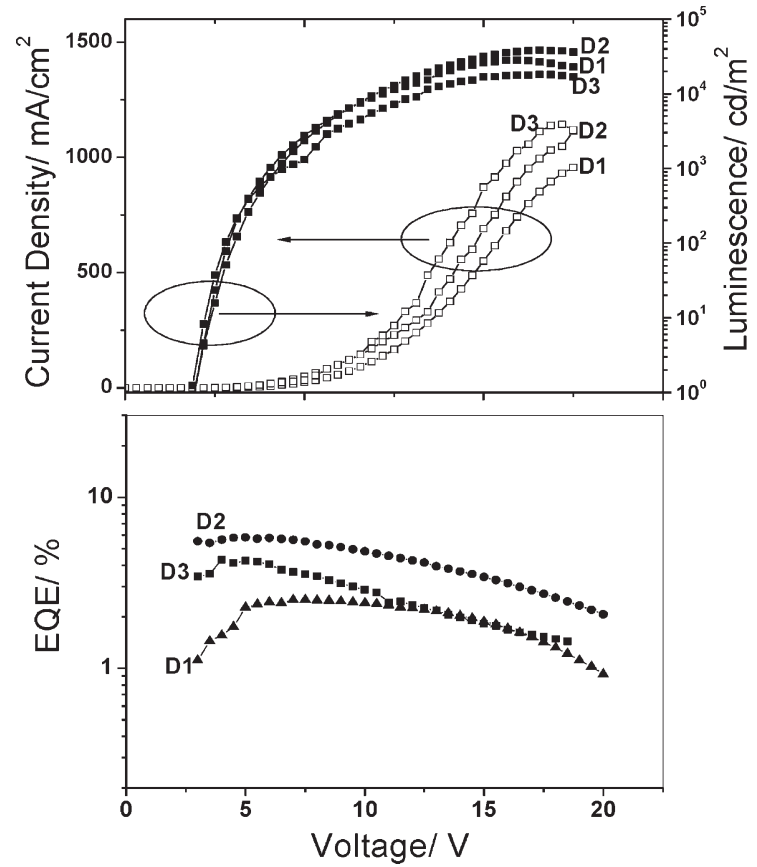

Figure 2. $I-V-L$ properties of the undoped devices $\operatorname{Dn}(n=1,2,3)$ with configuration of ITO/PEDOT:PSS $(50 \mathrm{~nm}) / \mathrm{Dn}(60 \mathrm{~nm}) / \mathrm{TPBI}(30 \mathrm{~nm}) /$ $\mathrm{LiF}(0.5 \mathrm{~nm}) / \mathrm{Al}(150 \mathrm{~nm})$.

0.838 Debye for D1, D2, and D3, correspondingly. The stronger interactions between D1 molecules will induce more serious aggregation and red shift in the absorption and luminescent spectra, due to a larger dipole moment. ${ }^{[17]}$ The low EQE of device D1 may result from the aggregation of emissive molecules. This conjecture gave us a hint to improve the device performance by doping these blue-light-emitting molecules into a host matrix, in order to reduce the aggregation and self-quenching. 4, $4^{\prime}-N, N^{\prime}$ dicarbazole-biphenyl (CBP) was used as host matrix (Fig. 3). We found that when we replaced the undoped layer of Dn by a CBP layer doped with 4\% Dn as the emissive zone, the emissions peaked at 446, 445, and $439 \mathrm{~nm}$. The CIE color coordinates of the emissions from these doped devices are $(0.147,0.130)$, $(0.149,0.132)$ and $(0.151,0.088)$, all of which are in the pureblue emission limit. The highest EQE of the devices are 8.1, 8.6, and $8.2 \%$ for D1, D2, and D3, respectively. The similarity of EQE from doped devices, compared with the distinction of EQE from undoped ones, indicates that interactions between the emissive molecules dominated the performance of the devices.

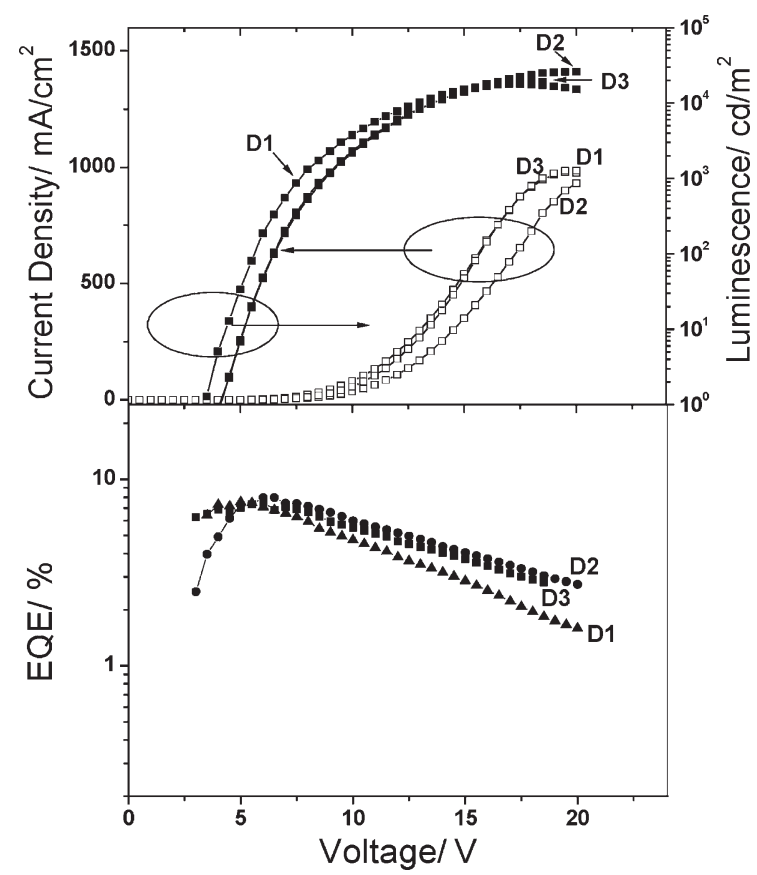

Figure 3. $I-V-L$ properties of the doped devices $\mathrm{Dn}(n=1,2,3)$ with configuration of ITO/PEDOT:PSS(50 nm)/CBP:4\% Dn $(60 \mathrm{~nm}) / \mathrm{TPBI}(30 \mathrm{~nm}) /$ $\operatorname{LiF}(0.5 \mathrm{~nm}) / \mathrm{Al}(150 \mathrm{~nm})$.

EQE of OLEDs can be estimated from $\eta_{\mathrm{EL}}=\eta_{\mathrm{oc}} \eta_{\mathrm{I}}$, where $\eta_{\mathrm{oc}}$ is outcoupling factor and $\eta_{\mathrm{I}}$ is the internal quantum efficiency (IQE). Note that we have reproduced an EQE of $1.2 \%\left(3.9 \mathrm{~cd} \mathrm{~A}^{-1}\right)$ from a controlled OLED with configuration of ITO/NPB $(40 \mathrm{~nm}) /$ tris-(8-hydroxy quinolato)aluminium (Alq) $(50 \mathrm{~nm}) / \mathrm{LiF}(0.5 \mathrm{~nm}) /$ Al $(150 \mathrm{~nm})$, using the same ITO-coated glass substrates and the same equipments for processing and measuring the present blue-light OLEDs. The value is in agreement with results reported for Alq-based OLEDs. ${ }^{[18]}$ Accordingly, the high EQE of the devices are not from enhanced out-coupling factors of the glass substrates or electrodes. We also fabricated an electrophosphorescent device using bis(2-phenylpyridine)(acetylacetonate) iridium(III) (Ir(ppy) $\left.2_{2}(\mathrm{acac})\right)$ doped in CBP at concentration of $10 \%$ to replace the blue-light emitters as the emitting layer in the same configuration as the blue-light devices. The EQE of the electrophosphorescent device was determined to be $11.3 \%$, which is consistent with reported values. ${ }^{[19]}$ Therefore, the high EQE of the blue-light devices are not due to the refractive index of the organic materials used. 
$\eta_{o c}$ is about $(22 \pm 3) \%$, as estimated from $\eta_{\mathrm{oc}}=1-\sqrt{1-1 / n^{2}}$, where $n$ is the refractive index of the emitting layer (normally is $(1.6 \pm 0.1)$ for organic solids). ${ }^{[20]}$ From the maximum EQE of the blue-light-emission devices, the maximum IQE is estimated to be $\approx 30 \%$ for undoped devices and $\approx 40 \%$ for doped devices. These values exceed the simple statistical upper limit of $25 \%$ for OLEDs, which assumes the formation of cross-sections of singlet and triplet excitons are equal. ${ }^{[21,22]}$ The triplet-to-singlet conversion in these oligomers is supposed to be inefficient because the spinorbit coupling is weak due to lack of heavy atoms. The possible reason that accounts for the high IQE is the high singlet-to-triplet exciton-formation cross-section ratio in conjugated systems. ${ }^{[23]}$ Following Shuai et al., ${ }^{[24]}$ the singlet exciton generation fraction reads

$\chi_{\mathrm{S}}=\sigma_{\mathrm{S}} /\left(\sigma_{\mathrm{S}}+3 \sigma_{\mathrm{T}}\right)$

$\frac{\sigma_{S}}{\sigma_{T}}=\frac{E_{b T}}{E_{b S}}$

where $\sigma_{S}$ and $\sigma_{T}$ represent the formation cross-sections of singlet and triplet excitons, $E_{b S}$ and $E_{b T}$ are the binding energies of the singlet and triplet excitons, respectively. $E_{b S}$ and $E_{b T}$ can be calculated from density functional theory (DFT) and timedependent DFT (TDDFT) as ${ }^{[25]}$

$E_{\mathrm{bS}}=E_{\mathrm{g}}-E_{\mathrm{S} 1}$

$E_{\mathrm{bT}}=E_{\mathrm{g}}-E_{\mathrm{T} 1}$

where $E_{g}$ is the HOMO-LUMO energy gap. $E_{S 1}$ and $E_{T 1}$ are excitation energies from ground state to the lowest excited singlet state and the lowest excited triplet state, respectively.

The calculated results are summarized in Table 3. The calculated formation cross-sections ratios of singlet over triplet excitons are 2.28, 2.51, and 3.16 for $\mathbf{D} 1, \mathbf{D} 2$, and $\mathbf{D} 3$. These are in line with the values calculated for some conjugated polymers and oligomers for OLEDs using the EOM/CCSD method. ${ }^{[26]}$ Correspondingly, the singlet exciton-generation fraction for D1, D2, and D3 are determined to be $43.2,45.5$, and $51.3 \%$. Our estimated IQEs are reasonable, since the singlet-generation fractions for these blue-light emitters are nearly two-fold the simple statistical limit.

In summary, highly efficient and stable deep-blue-lightemitting materials consisting of oligofluorenyl blocks and electron donating/electron withdrawing groups were synthesized for OLED applications. The maximum EQEs in solutionprocessing undoped and doped OLEDs reached $6.1 \%$ and $8.6 \%$, respectively. The devices also showed excellent stability, which is important for long-term operation.

Table 3. Calculation results of D1, D2, and D3 at B3LYP/6-31C* level.

\begin{tabular}{lccccccc}
\hline Compound & $E_{\mathrm{g}}[\mathrm{eV}]$ & $E_{\mathrm{S} 1}[\mathrm{eV}]$ & $E_{\mathrm{Tl}}[\mathrm{eV}]$ & $E_{\mathrm{bS}}[\mathrm{eV}]$ & $E_{\mathrm{bT}}[\mathrm{eV}]$ & $\sigma_{\mathrm{S}} / \sigma_{\mathrm{T}}$ & $\chi_{\mathrm{S}}[\%]$ \\
\hline D1 & 3.197 & 2.841 & 2.383 & 0.356 & 0.814 & 2.28 & 43.2 \\
D2 & 3.065 & 2.790 & 2.376 & 0.275 & 0.689 & 2.51 & 45.5 \\
D3 & 3.007 & 2.808 & 2.379 & 0.199 & 0.628 & 3.16 & 51.3 \\
\hline
\end{tabular}

\section{Experimental}

Synthesis: 4-(9H-carbazol-9-yl)benzeneamine (A) was prepared through the Ullmann Reaction following reported procedures [27]. Compounds C1, C2, C3 were prepared through reported procedures [28]. A mixture of $\mathbf{A}$ $(0.258 \mathrm{~g}, 1 \mathrm{mmol}), \mathbf{B n}(n=1,2,3,3 \mathrm{mmol})$, sodium tert-butoxide $(0.96 \mathrm{~g}$, $10 \mathrm{mmol}$ ), 1,1'-Bis(diphenylphosphino)ferrocene (DPPF, $44 \mathrm{mg}$ ), and $\mathrm{Pd}(\mathrm{OAc})_{2}(9 \mathrm{mg})$ in toluene $(12 \mathrm{~mL})$ was heated to $110^{\circ} \mathrm{C}$ in an oil bath for $18 \mathrm{~h}$ under $\mathrm{N}_{2}$ atmosphere. The reaction mixture was poured into water and extracted with diethyl ether. The organic extracts were combined and washed with brine and dried with anhydrous $\mathrm{MgSO}_{4}$. The solvent was removed under reduced pressure, and the residue went through a silica-gel column to give products $\mathbf{C} 1, \mathbf{C} 2$, and $\mathbf{C} 3$ with yields of 68,53 and $59 \%$, respectively.

Compounds D1, D2, D3 were synthesized using this general procedure: a mixture of $\mathrm{Cn}(n=1,2,3,0.15 \mathrm{mmol})$, 4-cyanophenylboronic acid $(0.6 \mathrm{mmol})$, and tetrakis(triphenylphosphine) palladium $(3.4 \mathrm{mg}$, $0.003 \mathrm{mmol}$ ) was added to an air-free two-phase mixture of toluene $(15 \mathrm{~mL})$ and an aqueous $2 \mathrm{M} \mathrm{Na} \mathrm{CO}_{3}$ solution $(12 \mathrm{~mL})$. The resulting mixture was intensively stirred under an argon atmosphere at $110^{\circ} \mathrm{C}$ for $24 \mathrm{~h}$. The organic layer was separated and the aqueous phase was extracted with diethyl ether. The organic layers were combined and washed with brine $(2 \times 50 \mathrm{~mL})$ and dried over anhydrous $\mathrm{MgSO}_{4}$. The solvent was evaporated and the residue went through silica-gel column. The product was further purified by recrystallization in heptane twice.

D1: Yielding 0.147 g (87\%). ' $\mathrm{H}$ NMR $\left(400 \mathrm{MHz}, \mathrm{CDCl}_{3}, \delta\right): 8.172-8.153$ $(\mathrm{d}, J=7.6 \mathrm{~Hz}, 2 \mathrm{H}), 7.760-7.726(\mathrm{~m}, 10 \mathrm{H}), 7.686-7.666(\mathrm{~d}, J=8.0 \mathrm{~Hz}, 2 \mathrm{H})$, $7.595-7.575(\mathrm{dd}, J=8.0 \mathrm{~Hz}, 2 \mathrm{H}), 7.536(\mathrm{~s}, 2 \mathrm{H}), 7.500-7.424(\mathrm{~m}, 6 \mathrm{H})$, $7.371-7.349(\mathrm{~m}, 2 \mathrm{H}), 7.320-7.285(\mathrm{t}, J=6.8 \mathrm{~Hz}, 4 \mathrm{H}), 7.206-7.186(\mathrm{dd}$, $J=8.0 \mathrm{~Hz}, 2 \mathrm{H}), 1.968(\mathrm{~m}, 8 \mathrm{H}), 1.097(\mathrm{~m}, 24 \mathrm{H}), 0.758(\mathrm{~m}, 2 \mathrm{H}) ;{ }^{13} \mathrm{C}$ NMR $\left(100 \mathrm{MHz}, \mathrm{CDCl}_{3}, \delta\right): 153.165,152.096,147.638,146.512,141.956$, $141.454,137.728,136.351,133.259,132.955,132.100,128.310,128.190$, $128.025,126.727,126.250,124.241,123.760,121.788,121.364,120.721$, $120.253,120.154,119.742,119.388,110.397,110.130,55.772,40.681$, $31.935,30.035,24.327,22.887,14.330$. MS (MALDI): $\mathrm{m} / \mathrm{z}$ (100\%): calcd for $\mathrm{C}_{82} \mathrm{H}_{84} \mathrm{~N}_{4}, 1124.669$; found, 1124.746. Anal. calcd for $\mathrm{C}_{82} \mathrm{H}_{84} \mathrm{~N}_{4}$ : C 87.50, H 7.52, N 4.98; found: C 87.34, H 7.33, N 5.06 .

D2: Yielding $0.20 \mathrm{~g}(75 \%)$. ${ }^{7} \mathrm{H}$ NMR $\left(400 \mathrm{MHz}, \mathrm{CDCl}_{3}, \delta\right): 8.183-8.163$ $(\mathrm{d}, J=8.0 \mathrm{~Hz}, 2 \mathrm{H}), 7.843-7.824(\mathrm{~d}, J=7.6 \mathrm{~Hz}, 4 \mathrm{H}), 7.777-7.745(\mathrm{~m}, 10 \mathrm{H})$, 7.707-7.582 (m, 14H), 7.527-7.506 (d, J=8.4 Hz, 2H), 7.460-7.447 (m, $4 \mathrm{H}), 7.396-7.376(\mathrm{~d}, J=8.0 \mathrm{~Hz}, 2 \mathrm{H}), 7.343-7.293(\mathrm{~m}, 4 \mathrm{H}), 7.231-7.210(\mathrm{~d}$, $J=8.4 \mathrm{~Hz}, 2 \mathrm{H}), 2.106(\mathrm{~m}, 16 \mathrm{H}), 1.141(\mathrm{~m}, 48 \mathrm{H}), 0.800-0.755(\mathrm{~m}, 40 \mathrm{H})$; ${ }^{13} \mathrm{C}$ NMR $\left(100 \mathrm{MHz}, \mathrm{CDCl}_{3}, \delta\right): 153.075,152.502,152.279,151.876$, $147.906,147.266,146.589,142.027,141.578,140.618,140.239,139.780$, $138.230,136.934,132.958,131.715,128.102,126.675,126.237,124.306$, $123.866,123.761,121.962,121.895,121.800,121.049,120.668,120.199$, $119.994,119.878,119.356,111.088,110.197,55.852,55.708,40.716$, $31.947,31.809,30.063,30.010,24.364,24.237,22.884,14.339,14.289 . \mathrm{MS}$ (MALDI): $m / z$ (100\%): calcd for $\mathrm{C}_{132} \mathrm{H}_{148} \mathrm{~N}_{4}, 1790.173$; found, 1790.413 . Anal. calcd for $\mathrm{C}_{132} \mathrm{H}_{148} \mathrm{~N}_{4}$ : C 88.54, H 8.33, N 3.13; found: $\mathrm{C} 88.62, \mathrm{H} 8.25$, N 3.14.

D3: Yielding $0.20 \mathrm{~g}(60 \%){ }^{\top} \mathrm{H}$ NMR $\left(400 \mathrm{MHz}, \mathrm{CDCl}_{3}, \delta\right): 8.182-8.163$ $(\mathrm{d}, J=7.6 \mathrm{~Hz}, 2 \mathrm{H}), 7.848-7.828(\mathrm{~d}, J=8.0 \mathrm{~Hz}, 8 \mathrm{H}), 7.779-7.747(\mathrm{~m}, 10 \mathrm{H})$, 7.710-7.7.584 (m, 22H), 7.529-7.508 (d, J=8.4 Hz, 2H), 7.478-7.447 (m, $4 \mathrm{H}), 7.399-7.377(\mathrm{~d}, J=8.8 \mathrm{~Hz}, 2 \mathrm{H}), 7.344-7.293(\mathrm{~m}, 4 \mathrm{H}), 7.232-7.212(\mathrm{~d}$, $J=8.0 \mathrm{~Hz}, 2 \mathrm{H}), 2.106(\mathrm{~m}, 24 \mathrm{H}), 1.135(\mathrm{~m}, 72 \mathrm{H}), 0.790(\mathrm{~m}, 60 \mathrm{H}) ;{ }^{13} \mathrm{C} \mathrm{NMR}$ $\left(100 \mathrm{MHz}, \mathrm{CDCl}_{3}, \delta\right): 153.059,152.508,152.230,151.842,147.899$, $147.200,146.582,142.001,141.602,141.524,141.017,140.920,140.723$, $140.608,140.472,140.390,140.299,139.816,138.230,136.968,132.976$, $131.629,128.115,126.704,126.571,126.246,124.284,123.830,123.724$, $121.957,121.862,121.774,121.018,120.684,120.371,120.186,119.970$, $119.863,119.416,111.040,110.215,55.845,55.743,55.700,40.731$, $31.968,31.828,30.033,24.363,24.243,22.910,14.350$. MS (MALDI): $\mathrm{m} / \mathrm{z}$ (100\%): calcd for $\mathrm{C}_{182} \mathrm{H}_{212} \mathrm{~N}_{4}, 2455.677$; found, 2455.095. Anal. calcd for $\mathrm{C}_{182} \mathrm{H}_{212} \mathrm{~N}_{4}$ : C 89.02, H 8.70, N 2.28; found: C 88.96, H 8.99, N 2.41.

Device Fabrication and Measurement: For a single layer of $\mathrm{Dn}(n=1,2$, 3) as emission zone, $10 \mathrm{mg}$ Dn was dissolved in $1 \mathrm{~mL}$ toluene and filtered through a $0.2 \mu \mathrm{m}$ polytetrafluoroethylene (PTFE) filter for device 
fabrication. For a Dn-doped CBP layer as emission zone, $0.8 \mathrm{mg} \mathrm{Dn}$ and $20 \mathrm{mg}$ CBP were dissolved in $4 \mathrm{~mL}$ chloroform and filtered through a $0.2 \mu \mathrm{m}$ PTFE filter for device fabrication. The light-emitting devices were prepared on patterned ITO-coated glass substrates, which had been cleaned with a detergent solution, distilled water, acetone, and ethanol sequentially in an ultrasonic bath. The cleaned substrates were treated with oxygen-argon plasma and spin-coated with $50 \mathrm{~nm}$ of PEDOT doped with PSS, followed by drying at $120^{\circ} \mathrm{C}$ in air for $15 \mathrm{~min}$. The solutions of emissive materials were spin-coated to form the emitting layer with a thickness of about $60 \mathrm{~nm}$, and transferred into a chamber under vacuum of $1 \times 10^{-5} \mathrm{~Pa}$. A $30 \mathrm{~nm}$ of 1,3,5-tris (phenyl-2-benzimidazolyl)benzene (TPBI) was deposited onto the surface of the emitting layer for electron injection and hole blocking. The cathode was composed of $0.5 \mathrm{~nm} \mathrm{LiF}$ and $150 \mathrm{~nm}$ $\mathrm{Al}$, which were successively thermally deposited. All measurements were carried out in air at room temperature except where specifically indicated. The current-voltage-luminance $(I-V-L)$ characteristics of the devices were recorded using a Keithley 2420 source meter and a calibrated photodiode. EL spectra were recorded using an Ocean Optics USB2000 miniature fiber optic spectrometer. EQEs were calculated using $I-V-L$ data and EL spectra of the devices, assuming the Lambertian distribution of the EL emission [29].

Quantum Chemistry Calculation: To reduce the computational time, hexyl group was replaced by methyl group in the oligomers, since this does not affect the optical and electronic properties significantly [30]. DFT and TDDFT calculations were carried out using the exchange-correlation functional of B3LYP [31]. The molecular geometries were optimized in Cartesian coordinates without any symmetries (maximum degrees of freedom) using 6-31C* basis set in Gaussian 03 program suite [32].

\section{Acknowledgements}

The authors would like to acknowledge the financial support from Institute of Materials Research \& Engineering (IMRE). C.-G. Zhen also acknowledges support through a MMPEI-Rackham Energy Fellowship at the University of Michigan.

Received: January 11, 2009

Revised: February 4, 2009

Published online: March 26, 2009

[1] C. W. Tand, S. A. Vanslyke, Appl. Phys. Lett. 1987, 51, 913.

[2] R. H. Friend, R. W. Gymer, A. B. Holmes, J. H. Burroughes, R. N. Marks, C. Taliani, D. D. C. Bradley, D. A. Dos Santos, J. L. Bredas, M. Logdlund, W. R. Salaneck, Nature 1999, 397, 121.

[3] A. J. Heeger, Solid State Commun. 1998, 107, 673.

[4] M. A. Baldo, M. E. Thompson, S. R. Forrest, Nature 2000, 403, 750.

[5] J. N. Bardsley, IEEE J. Sel. Top. Quantum Electron. 2004, 10, 3.

[6] Y. R. Sun, N. C. Giebink, H. Kanno, B. W. Ma, M. E. Thompson, S. R. Forrest, Nature 2006, 440, 908.

[7] D. Vak, B. Lim, S. H. Lee, D. Y. Kim, Org. Lett. 2005, 7, 4229.

[8] I. D. Rees, K. L. Robinson, A. B. Holmes, C. R. Towns, R. O'Dell, Mater. Res. Bull. 2002, 27, 451

[9] A. P. Kulkarni, S. A. Jenekhe, Macromolecules 2003, 36, 5285.
[10] R. C. Chiechi, R. J. Tseng, F. Marchioni, Y. Yang, F. Wudl, Adv. Mater. 2006 , $18,325$.

[11] A. W. Grice, D. D. C. Bradley, M. T. Bernius, M. Inbasekaran, W. W. Wu, E. P. Woo, Appl. Phys. Lett. 1998, 73, 629.

[12] M. C. Hung, J. L. Liao, S. A. Chen, S. H. Chen, A. C. Su, J. Am. Chem. Soc. 2005, 127, 14576.

[13] K. L. Chan, M. J. McKiernan, C. R. Towns, A. B. Holmes, J. Am. Chem. Soc. 2005, 127, 7662.

[14] K. R. J. Thomas, J. T. Lin, Y. T. Tao, C. H. Chuen, J. Mater. Chem. 2002, 12 , 3516.

[15] T. H. Huang, J. T. Lin, L. Y. Chen, Y. T. Lin, C. C. Wu, Adv. Mater. 2006, 18 602.

[16] H. Y. Zhang, C. Huo, J. Y. Zhang, P. Zhang, W. J. Tian, Y. Wang, Chem. Commun. 2006, 281.

[17] M. A. Baldo, Z. G. Soos, S. R. Forrest, Chem. Phys. Lett. 2001, 347, 297.

[18] C. W. Tang, S. A. Vanslyke, C. H. Chen, J. Appl. Phys 1989, 65, 3610.

[19] S. Lamansky, P. Djurovich, D. Murphy, F. Adbel-Razzaq, H.-E. Lee, C. Adachi, P. E. Burrows, S. R. Forrest, M. E. Thompson, J. Am. Chem. Soc. 2001, 123, 4304

[20] B. E. A. Saleh, M. C. Teich, in, Fundamentals of Photonics, Wiley, New York 1991.

[21] A. R. Brown, K. Pichler, N. C. Greenham, D. D. C. Bradley, R. H. Friend, A. B. Holmes, Chem. Phys. Lett. 1993, 210, 61.

[22] M. Wohlgenannt, X. M. Jiang, Z. V. Vardeny, R. A. J. Janssen, Phys. Rev. Lett. 2002, 88, 197401.

[23] Y. Cao, I. D. Parker, G. Yu, C. Zhang, A. J. Heeger, Nature 1999, 397, 414

[24] S. W. Yin, L. P. Chen, P. F. Xuan, K. Q. Chen, Z. Shuai, J. Phys. Chem. B 2004, 108, 9608

[25] M. T. Sun, P. Kjellberg, W. J. D. Beenken, T. Pullerits, Chem. Phys. 2006, 327, 474.

[26] L. P. Chen, L. Y. Zhu, Z. G. Shuai, J. Phys. Chem. A 2006, 110, 13349.

[27] A. Kimoto, J. S. Cho, M. Higuchi, K. Yamamoto, Macromolecules 2004, 37, 5531.

[28] F. E. Goodson, S. I. Hauck, J. F. Hartwig, J. Am. Chem. Soc. 1999, 121, 7527.

[29] D. O'Brien, A. Bleyer, D. G. Lidzey, D. D. C. Bradley, T. Tsutsui, J. Appl. Phys. 1997, 82, 2662.

[30] J. C. Sancho-Garcia, C. L. Foden, I. Grizzi, G. Greczynski, M. P. de Jong, W. R. Salaneck, J. L. Bredas, J. Cornil, J. Phys. Chem. B 2004, 108, 5594.

[31] A. D. Becke, J. Chem. Phys. 1993, 98, 5648.

[32] Gaussian 03, Revision C.02, M. J. Frisch, G. W. Trucks, H. B. Schlegel, G. E. Scuseria, M. A. Robb, J. R. Cheeseman, J. A. Montgomery, Jr, T. Vreven, K. N. Kudin, J. C. Burant, J. M. Millam, S. S. Iyengar, J. Tomasi, V. Barone, B. Mennucci, M. Cossi, G. Scalmani, N. Rega, G. A. Petersson, H. Nakatsuji, M. Hada, M. Ehara, K. Toyota, R. Fukuda, J. Hasegawa, M. Ishida, T. Nakajima, Y. Honda, O. Kitao, H. Nakai, M. Klene, X. Li, J. E. Knox, H. P. Hratchian, J. B. Cross, V. Bakken, C. Adamo, J. Jaramillo, R. Gomperts, R. E. Stratmann, O. Yazyev, A. J. Austin, R. Cammi, C. Pomelli, J. W. Ochterski, P. Y. Ayala, K. Morokuma, G. A. Voth, P. Salvador, J. J. Dannenberg, V. G. Zakrzewski, S. Dapprich, A. D. Daniels, M. C. Strain, O. Farkas, D. K. Malick, A. D. Rabuck, K. Raghavachari, J. B. Foresman, J. V. Ortiz, Q. Cui, A. G. Baboul, S. Clifford, J. Cioslowski, B. B. Stefanov, G. Liu, A. Liashenko, P. Piskorz, I. Komaromi, R. L. Martin, D. J. Fox, T. Keith, M. A. Al-Laham, C. Y. Peng, A. Nanayakkara, M. Challacombe, P. M. W. Gill, B. Johnson, W. Chen, M. W. Wong, C. Gonzalez, J. A. Pople, Gaussian, Inc., Wallingford CT 2004. 